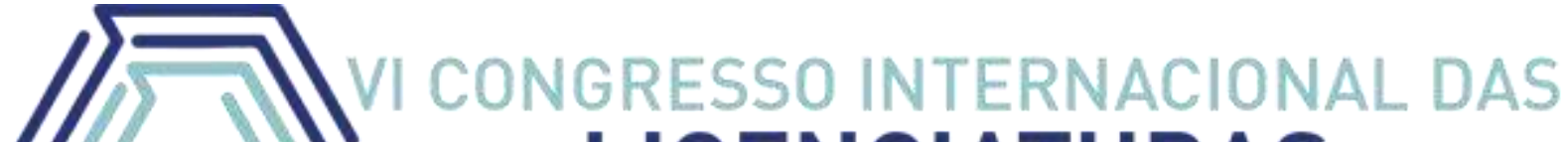 LICENCIATURAS COINTER - PDVL 2019
}

\section{DESAFIOS E PRÁTICAS DA LEITURA NOS ANOS INICIAIS DA ESCOLA MENINO JESUS EM SERRITA/PE}

\section{DESAFÍOS Y PRÁCTICAS DE LECTURA EN LOS PRIMEROS AÑOS DE BOY JESUS SCHOOL EN SERRITA / PE}

\section{CHALLENGES AND READING PRACTICES IN THE EARLY YEARS OF BOY JESUS SCHOOL IN SERRITA / PE}

\author{
Apresentação: Comunicação Oral
}

Maria da Conceição Lopes Bem Martins ${ }^{1}$; João Felix da Silva ${ }^{2}$; Geraldo Martins de Oliveira Junior $^{3}$; Maria das Graças Bento ${ }^{4}$

DOI: $\underline{\text { https://doi.org/10.31692/2358-9728.VICOINTERPDVL.2019.0003 }}$

\begin{abstract}
Resumo
O presente artigo tem por objetivo evidenciar a importância da leitura para a formação intelectual e social do aluno e com a finalidade de chamar a atenção dos mediadores desse processo em relação à necessidade de estratégias e recursos adequados para a prática leitora destes. Enfatizou-se, ainda, sobre a compreensão dos processos de alfabetização e letramento procurando diferenciá-los, para que essas especificidades possam ser compreendidas com clareza, ressaltando que são processos diferentes, porém que devem ser trabalhados juntos. Preocupou-se, também em discutir teoricamente a cerca da literatura infantil e sua contribuição para a formação de leitores, é possível perceber que as crianças devem estar sempre em contato com os livros tanto na escola, quanto na família, para despertar esse prazer pela leitura e um suporte de suma importância são os textos literários. Destacou-se, o apoio do Programa de Residência Pedagógica para o aperfeiçoamento do residente através de teoria e prática em sala de aula com projetos de intervenção colaborando na formação de leitores fluentes. O aporte teórico utilizado para o trabalho, advêm dos autores, Cavalcanti (2009), Freire (1995), Soares (2003), Martins (1984) entre outros. Com base nessa temática nota-se que os desafios na prática da leitura são inúmeros, más que devem ser trabalhados para desenvolver o senso crítico dos estudantes. A metodologia usada é de caráter qualitativo, bibliográfico e de estudo de caso. Concluímos com esse trabalho, que a leitura exerce um papel essencial na formação do aluno. Por meio dela, ele aprende a se comunicar e a dialogar com o mundo ao seu redor.
\end{abstract}

Palavras-Chave: Leitura, Alfabetização, Prática, Letramento.

\footnotetext{
${ }^{1}$ Graduanda em Pedagogia, FACHUSC, conceilobem@ @otmail.com

${ }^{2}$ Psicopedagogo, FIP, joaofelixserrita@hotmail.com

${ }^{3}$ Mestrando, Universidade Federal de Pernambuco - UFPE, geraldomarthins@ hotmail.com

${ }^{4}$ Mestre, Universidade Católica de Pernambuco, professoragracabento@hotmail.com
} 


\title{
Resumen
}

Este artículo pretende resaltar la importancia de la lectura para la educación intelectual y social del estudiante y con el propósito de llamar la atención de los mediadores de este proceso en relación con la necesidad de estrategias y recursos adecuados para su práctica de lectura. También enfatizó la comprensión de la alfabetización y los procesos de alfabetización, tratando de diferenciarlos, de modo que estas especificidades puedan entenderse claramente, enfatizando que son procesos diferentes, pero deben trabajarse en conjunto. Preocupados, también discutiendo teóricamente sobre la literatura infantil y su contribución a la formación de lectores, es posible darse cuenta de que los niños siempre deben estar en contacto con libros tanto en la escuela como en la familia, para despertar este placer leyendo Y un soporte muy importante son los textos literarios. Se destacó el apoyo del Programa de Residencia Pedagógica para el mejoramiento del residente a través de la teoría y la práctica en el aula con proyectos de intervención que colaboran en la formación de lectores con fluidez. El soporte teórico utilizado para el trabajo proviene de los autores Cavalcanti (2009), Freire (1995), Soares (2003), Martins (1984) y otros. Sobre la base de este tema, se observa que los desafíos en la práctica de la lectura son numerosos, pero se deben trabajar para desarrollar el sentido crítico de los estudiantes. La metodología utilizada es cualitativa, bibliográfica y de estudio de caso. Concluimos de este trabajo que la lectura juega un papel esencial en la educación de los estudiantes. A través de él, aprende a comunicarse y dialogar con el mundo que lo rodea.

Palabras clave: Lectura, Alfabetización, Práctica, Alfabetización.

\begin{abstract}
The purpose of this article is to highlight the importance of reading for the intellectual and social formation of the student and with the purpose of drawing the attention of the mediators of this process in relation to the need for adequate strategies and resources for the reading practice of these students. It was also emphasized the understanding of the literacy and literacy processes in order to differentiate them, so that these specificities can be clearly understood, emphasizing that they are different processes, but that they must be worked together. It has also been concerned with the theoretical discussion of children's literature and its contribution to the formation of readers, it is possible to realize that children should always be in contact with books both at school and in the family to awaken this pleasure by reading and literary texts are of paramount importance. It was highlighted the support of the Pedagogical Residency Program for the improvement of the resident through theory and practice in the classroom with intervention projects collaborating in the training of fluent readers. The theoretical contribution used for the study comes from the authors, Cavalcanti (2009), Freire (1995), Soares (2003), Martins (1984) and others. Based on this theme it is noticed that the challenges in the practice of reading are innumerable, but they must be worked on to develop students' critical sense. The methodology used is qualitative, bibliographic and case study. We conclude with this work, that reading plays an essential role in the formation of the student. Through it, he learns to communicate and to dialogue with the world around him.
\end{abstract}

Keywords: Reading. Literacy. Practice. Literature. 


\section{Introdução}

O referido trabalho apresenta-se como um estudo de caso na Escola Municipal Menino Jesus com uma turma de $2^{\circ}$ Ano do Ensino Fundamental dos Anos Iniciais em Serrita/PE e tem como objetivo desenvolver o senso crítico dos discentes no processo da aquisição da leitura, fazendo o uso das contribuições que essa prática promove. Quanto aos objetivos específicos adotamos possibilitar o acesso aos diversos tipos de leitura na escola, buscando formar leitores fluentes; despertar o prazer da leitura através de estratégias e procedimentos para um resultado significativo e verificar como a leitura pode desenvolver o senso crítico do estudante. $\mathrm{O}$ presente artigo foi produzido através de pesquisas bibliográficas, estudo de caso e observações relatando questões relevantes sobre os desafios no processo de alfabetização.

A leitura é responsável por contribuir, de forma significativa, à formação do indivíduo, influenciando-o a analisar a sociedade, seu dia a dia e, de modo particular, ampliando e diversificando visões e interpretações sobre o mundo. Vale ressaltar que a formação de um leitor crítico se faz a partir do momento em que o mesmo é influenciado em diversas situações do cotidiano e esse incentivo à leitura deve partir do professor em sala de aula, da família e da sociedade desde infância, tornando-os indivíduos de visão transformadora.

Este artigo parte da atual realidade na qual se encontra a prática da leitura nas salas de aula do ensino público. Nota-se que os alunos apresentam certa fragilidade em realizar leituras e compreende-las. Mas percebe-se que ás vezes tudo isso ocorre por falta de estímulo e acesso a essa prática que deveria ser contínua.

Nesse trabalho, é notável um grande problema, explícito a seguir: porque a maioria dos estudantes do Ensino Fundamental dos Anos Iniciais apresenta dificuldades em interpretar diversas leituras encontradas no âmbito escolar? O estudo apresenta os seguintes tópicos: o primeiro fala da prática da leitura no espaço escolar, o segundo sobre a importância da alfabetização e letramento no processo da leitura, o terceiro relata a contribuição da literatura infantil na formação de leitores e o último mostra um olhar reflexivo sobre o processo de leitura na perspectiva das vivências no Programa Residência Pedagógica.

\section{A prática da leitura no espaço escolar}

A prática da leitura se faz presente na vida das pessoas desde o momento em que passam a compreender o mundo a sua volta. A leitura proporciona a descoberta de um mundo novo e 
fascinante. Para tanto, a apresentação da leitura para as crianças deve ser feita de uma maneira diferenciada e atrativa, para que assim elas possam ter uma visão prazerosa a respeito do ato de ler, de modo que seja um prazer e um hábito que ela acrescentará em sua vida, e no espaço escolar se torna essencial criar essa trajetória na rotina dos discentes. Uma das formas de incentivar as crianças a lerem é apresentá-las a livros que estimulem o hábito de ler pelo prazer. A partir daí elenca-se diversas vantagens, como a de que elas conheçam mundos novos e realidades diferentes para que, desta forma, elas possam construir sua própria linguagem, oralidade, valores, sentimentos e idéias, essas tais, que a criança levará para o resto da vida. Assim, a escola tem o dever de fornecer a continuidade ao desenvolvimento da leitura, tanto da leitura de mundo quando à escrita, ao indivíduo. Ela tem o papel de formar um cidadão crítico, envolvido com as causas sociais e preparado para diversas situações.

A leitura é uma atividade essencialmente cognitiva que requer do leitor atenção, concentração e esforço mental para que se chegue à meta final da leitura, a saber, uma boa compreensão do objeto lido, dizendo que a leitura é um processo de compreensão de expressões formais e simbólicas, não importando por meio de que linguagem.

\footnotetext{
Não basta que a escola promova o lúdico, a brincadeira e a leitura dentro de um clima de prazer. É fundamental que aprenda a ler e a gostar de ler tenha um sentido na vida de cada um. Que o leitor se sinta identificado como o lido, que possa exercitar-se numa aprendizagem importante sobre o mundo, as pessoas, a natureza, as lutas, a dor e o amor. (CAVALCANTI, 2009, p. 79)
}

A autora é bem clara quando coloca que o desafio principal é fazer com que os alunos aprendam ler lendo, ler para se aprender a ler. Partindo desse pressuposto, o professor pode ler tudo ou quase tudo na sala de aula, desde jornais, revistas, até o que a imaginação permitir. O importante é que essa diversidade de textos ofereça ao aluno oportunidades de construção de sentidos, a partir de suas vivências.

Segundo a concepção sócio-interacionista Vigotscky a criança deve ser entendida como ser social e histórico que apresenta diferença de procedência socioeconômico, cultural, familiar, racial, de gênero, de faixa etária e que necessitam ser conhecidas respeitadas e valorizadas tendo como finalidade o desenvolvimento integral nos aspectos físico psicológico, intelectual e social contemplando a ação da família e da comunidade. O querer construir uma sociedade de leitores, vai além do sentimento do desejo, vai à atitude. Essa atitude deve ser planejada nas ações das atividades pedagógicas da escola, juntamente com todo com o corpo docente, desde atividades simples, como uma conotação de histórias a tarefas que exijam planejamentos mais elaborados. A forma que cada profissional da educação se engajar 
validará o sucesso dos objetivos propostos na formação de leitores. Assim, ler não é simplesmente decodificar, lê é antes de tudo, um processo contínuo e vasto que cada momento é único e relevante no processo educacional de cada estudante.

Vejamos o que diz Freire (1995, p. 11-12): “A leitura do mundo precede a leitura da palavra, daí que a posterior leitura desta não possa prescindir da continuidade daquele. Linguagem e realidade se prendem dinamicamente".

A prática da leitura deve também proporcionar, uma leitura profunda ao cotidiano, de forma que o cotidiano seja lido e ampliado com uma visão concretizada. Compreender o que se ler é uma forma condicionada a reflexão da soma dos conhecimentos adquiridos, ao longo da vida estudantil. A leitura é o melhor exercício mental que se possa existir e quando praticada diariamente torna-se essencial e satisfatória.

Desta forma, Bamberger afirma que:

\begin{abstract}
A leitura favorece a remoção das barreiras educacionais de que tanto se fala, concedendo oportunidades mais justas de educação principalmente através da promoção do desenvolvimento da linguagem e do exercício intelectual, e aumenta a possibilidade de normalização da situação pessoal de um indivíduo. (BARBERGER, 2008, p. 11)
\end{abstract}

A partir da visão do autor, evidencia-se que a escola é um dos lugares de compartilhar conhecimentos e precisa priorizar a leitura com diversos ambientes que possam atrair os pequenos e futuros leitores como: bibliotecas, salas de leitura, exposição de diversos gêneros textuais e entre outros. Sempre lembrando que primeiramente os docentes, devem ter o hábito de ler para assim demonstrarem a importância de ser um admirador desse contexto maravilhoso. Diante de tudo isso, percebe-se que a leitura é extremamente importante para todos nós, não apenas por ser fundamental em nossa formação intelectual, mas também por permitir ampliar horizontes dando acesso a um universo infinito de informações, idéias e sonhos.

\title{
A importância da alfabetização e letramento no processo da leitura
}

A alfabetização é a ponte que liga ao conhecimento científico dos alunos, onde se descobre as letras os sons das palavras e sua grafia. Esse processo de alfabetização ocorre através da mediação entre a criança e a linguagem escrita, sendo fundamental a mediação do professor, pois é ele quem pode auxiliar seus alunos, seja parando ou acelerando uma explicação; ajustando o planejamento inicial quando houver necessidade; ampliando ou não determinados aspectos trabalhados e propondo atividades adequadas ao nível de 
aprendizagem dos alunos. Para Ferreiro (2011, p. 32), as reflexões empreendidas sobre esse aspecto nos levam a pensar "através de que tipos de práticas a criança é introduzida na língua escrita”. Há aquelas que possibilitam meios para que as crianças construam o conhecimento junto com o educador, e há outras que distanciam as crianças do aprendizado, tornando-as meros espectadores. Isto não se trata de um método novo de alfabetização, mas sim da maneira pela qual a escrita é introduzida. É necessário rever e sempre inovar as práticas e pensar na criança como alguém capaz de aprender.

O conceito de alfabetização é um processo que leva a aprendizagem inicial da leitura e escrita. Ou seja, alfabetizada é aquela pessoa que domina habilidades básicas para fazer uso da leitura e escrita.

Vejamos alguns conceitos de alfabetização. Para Val (2006, p. 19),

\begin{abstract}
Pode-se definir alfabetização como o processo específico e indispensável de apropriação do sistema de escrita, a conquista dos princípios alfabético e ortográfico que possibilitem ao aluno ler e escrever com autonomia. Noutras palavras, alfabetização diz respeito à compreensão e ao domínio do chamado "código" escrito, que se organiza em torno de relações entre a pauta sonora da fala e as letras (e outras convenções) usadas para representá-la, a pauta, na escrita.
\end{abstract}

Quando as crianças iniciam o processo de alfabetização inicial, estão repletas de curiosidade e disposição para se apropriar da leitura e escrita. Esse é o momento de estimulálas mesmas para o hábito da leitura e contato com a escrita, e uma das maneiras é o professor ler em voz alta para elas todos os dias histórias, poemas, letras de música, textos, notícias de revista e jornais entre outros recursos.

A alfabetização não possui receita pronta em relação ao método, pois a forma de aprendizagem de uma criança pode ser diferente da outra. $\mathrm{O}$ método aplicado em uma turma pode não ter o mesmo resultado em outra.

Alfabetização e letramento podem se confundir e se mesclarem, mas não é bem assim: ambos têm suas diferenças e necessitam de uma conceituação clara e objetiva, mostrando que embora sejam distintos, são indissociáveis.

[...] a alfabetização desenvolve-se no contexto de e por meio de práticas sociais de leitura e de escrita, isto é, através de atividades de letramento e, este, por sua vez só se pode desenvolver no contexto da e por meio da aprendizagem das relações fonema grafema, isto é, em dependência da alfabetização [...] (SOARES, 2004, p. 14).

Assim, podemos discorrer que alfabetização refere-se à aquisição da escrita por um grupo de indivíduos ou apenas um. E o letramento, refere-se aos aspectos sócios históricos da aquisição da escrita na sociedade. 
Sabemos que a sociedade, hoje, está cada vez mais centrada na escrita. Apenas saber ler e escrever, isto é, codificar e decodificar as palavras não são condições suficientes para ser letrado. O indivíduo apenas será um ser alfabetizado. Dessa forma, o sujeito não conseguirá corresponder com as exigências do mundo moderno. Sendo assim, alfabetizar letrando os alunos na escola torna-se um desafio grande para os professores.

A maioria dos alunos aprendem a ler e a escrever, se alfabetizam, mas nem sempre praticam a leitura e a escrita em seu cotidiano. A falta de hábito por tais práticas dificulta o desenvolvimento das competências necessárias para utilizá-las ou se envolverem nas práticas sociais da escrita.

Soares (2003, p. 31) defende que, "letramento é o resultado da ação de ensinar e aprender as práticas sociais de leitura e de escrita." Todo indivíduo que faz uso constante da leitura e da escrita em seu dia a dia, pode ser considerado letrado.

Sendo assim, um indivíduo se torna letrado quando demonstra conhecimento a língua falada e escrita. Mas uma pessoa pode ser letrada e não alfabetizada, pois o letramento nada mais é do que decodificar e interpretar o que estar ao seu redor. Podemos exemplificar com casos de analfabetos que por meio de leitura de imagens e sons interpretam o que lhe foi proposto.

De acordo com tais significações, a leitura, em muito ultrapassa aquilo que os olhos podem ver e a mente pode identificar e compreender. Ela pressupõe um conhecimento prévio das palavras e seus sentidos exigindo do leitor as habilidades para relacionar, interpretar, conhecer, sentir o que se está lendo, entre outros. Ou seja, para que a leitura aconteça não basta haver a visualização da palavra, objeto, figura, situação, o leitor terá de saber o que está vendo, identificar, decodificar, falar e interpretar tudo que lhe foi proposto.

No entanto, só recentemente passou-se a enfrentar esta nova realidade social em que não basta apenas saber ler e escrever, é preciso também saber fazer uso do ler e do escrever, saber responder às exigências de leitura e de escrita que a sociedade faz continuamente. Britto (2008, p. 3) reforça essa idéia quando diz:

Ser letrado significa, acima de tudo, ser funcionalmente alfabetizado, isto é, ser capaz de usar de escritas para a realização das tarefas cotidianas características da sociedade urbano-industrial. Em outras palavras, o letramento, deste ponto de vista, se resume ao fato de o modo de produção supor um uso de escrita que permita aos indivíduos operar com as instruções de trabalho e normas de conduta e de vida.

É possível perceber que, para que haja a leitura de fato é necessário que o leitor tenha o domínio da alfabetização e do letramento. Ou seja, capaz de desenvolver uma leitura crítica 
do mundo através da interpretação. Para isso, é preciso que a leitura seja uma prática constante no processo educacional.

\section{A contribuição da literatura infantil na formação de leitores}

A literatura infantil proporciona às crianças diferentes experiências com a linguagem e com os sentidos, ou seja, possibilita o seu desenvolvimento linguístico e cognitivo. Permitindo assim, que elas possam ter acesso à leitura e a escrita de maneira divertida, pois quanto mais as crianças lerem, melhores desenvolvimentos na escrita obterão. Lendo constantemente, a criança consegue compreender e interpretar diversas situações. Por isso, é importante aproximar as crianças dos livros literários.

Cunha (1974, p. 45) afirma que:

A Literatura Infantil influi e quer influir em todos os aspectos da educação do aluno. Assim, nas três áreas vitais do homem (atividade, inteligência e afetividade) em que a educação deve promover mudanças de comportamento, a Literatura Infantil tem meios de atuar.

É através das emoções, imaginação e fantasias que a criança aprende, ou seja, entende a realidade, dando-lhe um significado. O uso da Literatura Infantil no processo de aquisição da leitura desperta na criança a curiosidade e a necessidade de ser um leitor, garantindo condições para que ela represente o mundo e a vida através das palavras, deixando criatividade, prazer e aprendizagem entrelaçados. Por este e vários outros motivos, verifica-se que a literatura deve estar presente cotidianamente na vida da criança, tanto em casa, com o auxílio dos pais, contando histórias, ou também deixar com que a criança conte sua própria versão, fazendo sua leitura com as imagens que o livro às remete, como na escola, com contação de histórias, idas à biblioteca, leituras individuais e coletivas. Enfim é desta maneira que se cria o hábito e o gosto pela leitura, e se formam bons leitores.

Quando se fala de literatura, fala-se de uma relação bastante estreita entre leitor e leitura. O leitor, no momento da leitura, ativa sua memória, relaciona fatos e experiências e entra em conflito com seus valores. Nesse aspecto a Literatura Infantil torna-se uma grande aliada da escola em suas várias possibilidades: divertindo, estimulando a imaginação, desenvolvendo o raciocínio e compreendendo o mundo.

Maia (2007, p. 67), afirma que: “[...] a literatura possibilita à criança uma apropriação lúdica do real, a convivência com um mundo ficcional, a descoberta do prazer proporcionado pelo texto literário e a apreensão do potencial lingüístico que esse texto expressa". Assim, a literatura infantil além de poder transportar o leitor a lugares imaginários e de lhe permitir 
vivenciar situações que a vida cotidiana não lhe proporcionaria, estimula o interesse pelo texto escrito enquanto linguagem capaz de concretizar ações e pensamentos humanos.

As dificuldades enfrentadas pelo docente em conquistar e manter o leitor se torna cada vez maior, sempre requer práticas pedagógicas intencionais e planejadas. O professor deve sempre observar a contribuição que a literatura infantil oferece para a formação de leitores, criando estratégias para que o estudante se torne um leitor com autonomia.

As estratégias e técnicas que o professor utiliza neste momento, precisam ser as mais variadas possíveis, permitindo aos alunos vivenciarem também a história, de maneiras diferentes. A dramatização, por exemplo, é uma das técnicas que desperta a atenção e permite observar e sentir a realidade da história. Acredita-se que esta técnica possibilita não só ao aluno desenvolver habilidades e competências, mas também ao professor, pois o estimula a expressar-se oralmente e corporalmente. (COELHO, 2000)

Nesse sentido, considera-se que a literatura faz parte do desenvolvimento escolar e da formação humana, pois através do hábito da leitura e contação de histórias, se possibilita que a criança desenvolva habilidades e competências, preparando-as para os desafios do mundo atual.

\section{Um olhar reflexivo sobre o processo de leitura na perspectiva das vivências no Programa Residência Pedagógica}

A CAPES instituiu o Programa de Residência Pedagógica, por meio da Portaria $\mathrm{n}^{\circ} 38$, de 28 de fevereiro de 2018, é uma das ações que integram a Política Nacional de Formação de professores e apóia as IES na implementação de projetos inovadores que estimulem a articulação entre teoria e prática nos cursos de Licenciaturas e tem por objetivo induzir o aperfeiçoamento da formação prática e promovendo a imersão do licenciando na escola de educação básica, a partir da segunda metade de seu curso. E o processo da Residência Pedagógica é uma etapa crucial da fase da formação do corpo docente, ou seja, a fase de construção de conhecimentos que irão proporcionar futuramente a autonomia profissional. É de suma importância destacar que os/as professores/as não são apenas transmissores do conhecimento, mas também aprendem durante o processo de ensino-aprendizagem. Todo esse desafio começa no estágio supervisionado que pode ser referido como um campo de construção do conhecimento, e junto ao Programa de Residência Pedagógica, ambos vão 
oportunizar um seguimento para o reconhecimento do território escolar e a prática educativa através da pesquisa.

Diante de tudo isso, aparece uma ideia que é com a prática que os acadêmicos de licenciatura poderão ter a oportunidade de conhecer a sua área de atuação futura, e somente colocando-se em contato com o acontecimento e vivenciando-o, é que se poderá conhecê-lo: "o despertar pedagógico começa a se manifestar apenas [...] no momento em que os alunos realizam estágios nas escolas" (ALTHAUS, 1997, p. 72). Tal perspectiva fragmenta a unidade teoria e prática e coloca a ênfase na prática como concepção da formação de professores.

O desenvolvimento das atividades propostas pelo Programa de Residência Pedagógica acontece com a parceria da escola campo: Escola Municipal Menino Jesus em Serrita/PE, onde o residente adquire um vasto conhecimento do processo de aprendizagem dos estudantes inseridos na referida instituição. É possível observar durante esse procedimento que o objetivo do PRP está sendo alcançado, onde o residente interage com a professora e com a turma a qual está estagiando, sempre realizando projetos que incentivam os discentes no processo da leitura e escrita, auxiliando para a formação de excelentes leitores. Percebe-se que não é uma tarefa fácil conseguir alfabetizar letrando e ainda despertar a curiosidade dos alunos para se relacionarem no mundo transformador da leitura.

O ensino da leitura e da escrita deve ser influenciado por toda a sociedade, mas a escola toma posto principal nessa função, delegando aos professores o trabalho de chamar a atenção dos alunos para a leitura e a desenvolver a escrita de forma a expressar idéias e pensamentos. Os professores têm, então, papel de mediadores do conhecimento. Segundo Martins (1984, p. 34):

\footnotetext{
A função do educador não seria precisamente ensinar e ler, mas a de criar condições para o educando realizar sua própria aprendizagem, conforme seus próprios interesses, necessidades, fantasias, segundo as dúvidas e exigências que a realidade lhe apresenta.
}

O papel da escola, é mais do que formar leitores, é de formar leitores que contextualizem o objeto lido com a sua carga de conhecimento, leitores que raciocinam e que mantenham uma relação crítica e opinativa com o que está sendo lido, que buscam entender o conteúdo transmitido com o objeto de leitura.

Portanto, torna-se essencial na trajetória acadêmica essa vivência na sala de aula para a preparação de futuros professores e a interação na aprendizagem de cada aluno para que haja uma parceria do residente com a escola no geral. Com isso, o programa não se limita somente 
a vivência na escola e na sala de aula, mas busca ajudar no ensino dos estudantes preparandoos para serem inseridos na sociedade como leitores e construtores de um mundo complexo.

\section{Metodologia}

A presente pesquisa é de traço qualitativo, ordem bibliográfica e de estudo de caso com um questionário respondido por uma professora da Escola Municipal Menino Jesus em Serrita/PE. Desta forma foi aplicado um questionário com três perguntas: Quais são os desafios encontrados em sala de aula para a formação de leitores fluentes? Atualmente a família está presente e auxiliando para o desenvolvimento no processo de leitura? De que forma a professora incentiva os estudantes a se ingressarem no mundo da leitura?

Desta forma é possível observar que o estudo de caso é a parte fundamental para uma pesquisa científica que é através das análises que podemos obter informações relevantes para o resultado da pesquisa. Vale destacar ainda, que a pesquisa bibliográfica tem como objetivo de reunir as informações e dados que servirão de base para a construção da investigação proposta a partir do tema em estudo, ou seja, todas as pesquisas realizadas no referido trabalho são de extrema relevância para resultados satisfatórios.

\section{Resultados e Discussão}

A pesquisa foi realizada em uma escola pública municipal, na cidade de Serrita/PE, feita por meio de um questionário com a professora do $2^{\circ}$ Ano do Ensino Fundamental, a qual identificamos com o nome fictício Carla Souza. A mesma respondeu com muita firmeza a importância de incentivos na formação de leitores críticos e ativos.

Vale lembrar que tal questionário é composto de três perguntas.

Quais são os desafios encontrados em sala de aula para a formação de leitores fluentes?

Para formar leitores requer vencer diversos desafios, então é preciso realizar um investimento significativo de materiais concretos, é necessário escolher bons livros literários, ambientes inovadores e salas atrativas. 
A professora ressalta que a prática da leitura deve ser diária e inovadora. O mediador desse processo deve propor diversas estratégias para que sejam vencidos os obstáculos presentes nessa rotina.

Atualmente a família está presente e auxiliando para o desenvolvimento no processo de leitura?

A família deveria ser a principal incentivadora na formação de um bom leitor. Infelizmente é uma realidade não concretizada. Porém a escola sempre trabalha para que a família se torne sua parceira em todos os aspectos, principalmente no processo de leitura.

A professora Carla Souza enfatiza que a família pode somar na formação do leitor, através de incentivos e parceria com a escola. A família tem a função de complementar à formação do indivíduo. No entanto a função da escola é educar, fornecer à educação formal. Porém ambas juntas podem transformar a criança em um cidadão preparado para conviver na sociedade interpretando o que a mesma lhe oferece.

De que forma a professora incentiva os estudantes a se ingressarem no mundo da leitura?

Oferecendo ambientes que despertam esse prazer pela leitura, propondo aulas diferentes como: rodas de leitura, leitura deleite, visita a biblioteca, enfim diversas estratégias as quais façam o aluno aprender a buscar essa prática no seu cotidiano.

Nessa questão, a professora aborda que é papel da escola fornecer aos estudantes, através da leitura, os instrumentos necessários para que eles consigam buscar, analisar, selecionar, relacionar, organizar as informações complexas do mundo contemporâneo e exercer a cidadania. As possibilidades de leitura para antes, durante e depois da leitura pretendem desenvolver a prática na formação do leitor, que para alcançar esse estágio de proficiência deve dominar os processamentos básicos da leitura.

Desse modo, as estratégias de compreensão e de interpretação representam a probabilidade de proporcionar meios de amadurecimento e autonomia para o leitor em 
formação, prioridade da prática pedagógica, embora consciente das dificuldades inerentes ao processo, mas certos da capacidade de transformação nele contida.

\section{Conclusões}

Diante de todo o conteúdo exposto neste artigo, muito se tem a refletir, e fazer no que se refere às práticas de leituras no Ensino Fundamental dos Anos Iniciais. Auxiliar o aluno a tornar-se um leitor competente de textos é uma tarefa muito difícil. Para contornar essa dificuldade, não têm faltado propostas pedagógicas que, contribui no processo de ensino aprendizagem dos estudantes. A motivação está intimamente vinculada às relações afetivas que os alunos possam ir estabelecendo com a língua escrita, relação que deve ser cultivada pelos professores na escola e fora dela, com atividades que despertem a curiosidade das crianças, a atitude de pesquisa, o interesse pela descoberta, etc. Só com ajuda e confiança, a leitura deixará de ser uma prática enfadonha para alguns e poderá se converter naquilo que sempre deveria ser: um desafio estimulante. Com base nesse estudo observamos que a leitura não é neutra ela é constante, uma necessidade indispensável e necessária a todas as pessoas.

A pesquisa aponta um caminho certo para compreender a leitura, como elemento fundamental para a aproximação do leitor com o mundo que o cerca e que a prática proporciona o alargamento de possibilidades para sua efetivação. É preciso que essa prática de leitura comece no espaço escolar, pois muitos alunos não têm esse hábito de ler em casa, por isso a escola tem o papel fundamental de incentivar a leitura na educação. Desse modo, a escola é a porta do conhecimento que fornece as condições básicas para o aprendizado permanente.

A visão teórica deste trabalho em meio à leitura corrobora para a questão de uma educação de qualidade e atuante no Ensino Fundamental por parte do incentivo real e notório da leitura, para que cada estudante do seu espaço social e cultural tenha direito desse ato de ler expressivo e cognitivo. Ler é importante na escola porque é importante na sociedade. Quando o aluno lê, os sentidos e valores que possui acerca dos fatos do mundo, acerca da vida e das pessoas entram em contato com os valores e sentidos veiculados nos textos. Com isso, a leitura na sala de aula serve para o aluno aprender a participar das práticas sociais de leitura que acontecem em todos os espaços onde o mesmo poderá conviver.

A leitura é e sempre foi o meio mais efetivo do aprendizado e da interiorização de conhecimentos. Ler é, antes de tudo, pertencer a um meio que se renova a cada dia com 
diferentes formas, pensamentos e idéias, assim, estando alfabetizado e letrado. Destaca-se como solução que os educadores estimulem e incentivem os alunos para o ato de ler e escrever, buscando realizar projetos que enfatizem esse processo, materiais concretos, aulas atrativas, apoio da família, sempre motivando esses discentes. Dessa forma a prática da leitura é fundamental para o indivíduo compreender melhor o que passa a sua volta, permite a aproximação do sujeito com o conhecimento, amplia o entendimento, dá significado ao mundo das palavras, permite situar-se na sociedade de forma participativa, estabelecendo relações entre o que já sabe com a idéia do outro possibilitando ampliar seus conhecimentos.

Concluímos que a leitura é fundamentalmente importante para o processo de desenvolvimento do aluno na fase escolar, e que a leitura, sem sombra de dúvida é fonte de conhecimento, sabedoria e inspiração. Comprovando assim, que a leitura só é autêntica quando essa se faz presente de todo ciclo da vida escolar do aluno.

\section{Referências}

ABRAMOVICH, F. Literatura Infantil: Gostosuras e Bobices. $4^{\circ}$ ed. São Paulo: Scipione, 1994.

ALTHAUS, M. T. M. Didática: da análise de suas contribuições nos cursos de Licenciatura da Universidade Estadual de Ponta Grossa à análise de suas repercussões na prática pedagógica do professor de escola pública. Dissertação (Mestrado). UEPG. 1997.

BACHA, M. L. Leitura na Primeira Série. Rio de Janeiro: Livro Técnico, 1975.

BAMBERGER, R. Como incentivar o hábito de leitura. 7. Ed. São Paulo: Ática, 2008.

BRITTO, L. P. L. Práticas de letramento no ensino: leitura, escrita e discurso. São Paulo: Parábola Editorial; Ponta Grossa, PR: UEPG, 2008.

CAVALCANTI, J. Caminhos da literatura infantil e juvenil: dinâmicas e vivências na ação pedagógica. 3 ed. São Paulo: Paulus, 2009.

COELHO, N. N. Literatura infantil: teoria, análise, didática. $1^{\circ}$ ed. São Paulo: Moderna, 2000.

CUNHA, M. A. A. Como ensinar Literatura infantil. 3. Ed. São Paulo: Discubra, 1974, p. 45 .

FERREIRO, E. Reflexões sobre alfabetização. 26 ed. São Paulo: Cortez, 2011.

FREIRE, P. A importância do ato de ler em três artigos que se complementam. São Paulo: Cortez, 1989. 
LAJOLO, M. Do mundo da leitura para a leitura do mundo. São Paulo Ática, 2004.

MAIA, J. Literatura na formação de leitores e professores. São Paulo: Paulinas, 2007.

MARTINS, M. H. O que é literatura. São Paulo: Brasiliense, 1984.

SOARES, M. Letramento e Alfabetização: as muitas facetas. In: Revista Brasileira de Educação, 2003.

SOARES, M. Letramento: Um tema em três gêneros. Belo Horizonte: Autêntica 2004.

VAL, M. G. C. O que é ser alfabetizado e letrado? 1. Ed. Brasília: Ministério da Educação, 2006.

VYGOTSKY, L.S. A formação Social da mente. $6^{\circ}$ Ed. São Paulo, SP. Martins Fontes Editora LTDA, 1998.

ZILBERMAN, R. Como e por que ler a literatura infantil brasileira. Rio de Janeiro: Objetiva, 2005.

ZILBERMAN, R. A leitura na Escola. In: Leitura em Crise na Escola: as alternativas do professor. Porto Alegre: Mercado Aberto, 1986. 